\title{
Research on the Feasibility of Implementing PPP in the Chinese Secondary School EFL Context
}

\author{
$\mathrm{Si} \mathrm{Li} i^{1, *}$ \\ ${ }^{1}$ School of Foreign Languages, Dalian Neusoft University of Information, Dalian, Liaoning 116023, China \\ *Corresponding author.Email: lisi@neusoft.edu.cn
}

\begin{abstract}
As a form-based approach, whether Presentation-Practice-Production (PPP) is suitable for implementation in EFL classrooms has always been a debate. This paper aims to investigate whether it is feasible to implement PPP in the Chinese EFL context with a special focus on the secondary school. PPP theory covering its procedure, advantages and limitations is discussed, and then an interview is conducted to collect data. Finally, the conclusion is given.
\end{abstract}

Keywords: presentation, practice, production, EFL, secondary school

\section{INTRODUCTION}

Since the middle of 1960s, Presentation-PracticeProduction (PPP) has been considered as a useful and significant teaching procedure by teacher trainees [1]. It is one of the well-known form-based approaches with the emphasis that accuracy is the priority at each learning stage [2]. As opposed to form-based approaches, meaning-based approaches such as Task-based Language Teaching (TBLT) are based on the belief that even though learners produce some inaccurate language, it is easier to make progress when they are encouraged to use the language for real communication. In terms of the relationship between formbased and meaning-based approaches, Willis and Willis [2] draw a distinction: in a form-based approach, primary focus is on specified and isolated linguistic forms; teachers control the learning process; whether or not students can produce the accurate target forms is the assessing criterion. On the contrary, in a meaning-based approach, focus on meaning precedes focus on form; assessment is based on whether students can make the successful communication; the teacher acts as a participant and observer instead of a supervisor.

Although the debate between PPP and TBLT is increasing, few studies have been conducted on the implementation of the two approaches especially in Asian context. The focus of this paper is to explore whether it is feasible to apply traditional PPP in Chinese EFL context, in particular, in secondary school.

\section{PRESENTATION, PRACTICE AND PRODUCTION}

\subsection{PPP Procedure}

In PPP procedure, there are three steps: presentation, practice and production [3]. At the first stage, the teacher acting as provider and informant of input presents the new language, while students listen to and comprehend what the teacher presents [3]. At the second stage, students practice the new language items through techniques such as cueresponse drills (where the teacher nominates a student after providing a cue, for example, book, and then the student responds in an expected pattern, for instance, there is a book on the table.), individual repetition (where students repeat a word, phrase or sentence individually under the teacher's direction) and choral repetition (where students repeat a word, phrase or sentence together under the control of the teacher) [1]. It also should be noted that as students move to the next stage, the teacher's supervision is gradually reduced. At the third stage, students produce their own sentences rather than what the teacher directs them to say using the new language [4].

As it will be mentioned in Section 2.2 on the advantages of PPP, the teacher's control over the PPP cycle is the first feature. Second, PPP is a form-based approach. As a formbased approach, it pays special attention to specific linguistic forms of the target language and emphasizes accuracy rather than fluency in the learning process. It is best illustrated in the presentation and production stage. To be specific, in the presentation stage, the teacher focuses on explaining to the students how to use the linguistic forms correctly. The linguistic forms may include agreement features or verb endings, or even functional expressions such as complaints or compliments [5]. At the practice stage, students aim at achieving accuracy by practicing the linguistic forms in drills, exercises or dialogues. When mistakes occur in practicing certain sentence patterns, the teacher will correct them.

\subsection{Advantages of PPP}

According to Harmer [6], the PPP procedure is frequently followed in terms of teaching vocabulary, grammar patterns and dialogues. Its advantages are as follows: first, it brings teachers more convenience. The teacher has a clear instructional role in charge of the content and pace of the 
lesson, which is relatively easy for teachers, especially the new ones to organize the lesson and deal with the unpredictable elements in the classroom [7]. Second, the logic underlying PPP appeals to both teachers and learners. It reflects a notion according to which many alternative skills are learned, that is, practice makes perfect, and learning is a process of forming good habits by the automaticity of rules [9]. Third, with tangible and clear teaching objectives that can then lead to evaluation, PPP "lends itself very neatly to accountability" [8] (Skehan, 1998:94). In other words, the production stage is emphasized in PPP procedure; therefore, assessment of students' work can be straightforward and non-problematic, which assures teaching quality [9]. Fourth, the PPP model is especially effective in a grammar lesson. Careless [4] interviewed 12 teachers and 10 teacher educators to explore their perceptions of pros and cons of PPP and TBLT in the Hong Kong context, in which one teacher who preferred PPP to TBLT showed an opinion that PPP is condensed and clear-cut, the main points can be taught easily, so it is especially helpful to explain grammar.

\subsection{Limitations of PPP}

In the 1990s, PPP became under sustainable attack. First, PPP is regarded as lacking a ground foundation in second language acquisition. It is questionable in psychology or linguistics that learning comes from converting a particular form to automaticity through a number of repetitions [10]. Second, PPP presumes that accuracy precedes fluency. However, it is inevitable that learners experience a long period of making mistakes before using the target language fluently; besides, it is also possible that they are able to express their meanings fluently in the meanwhile [7]. Third, it is criticized that PPP is a teacher-centered rather than student-centered approach. Although teachers are familiar with the procedures and find it manageable, students may lose interest in the presentation and practice stage directed by teachers all the way [4]. As a consequence, during the free practice stage less self-motivated students may not produce the target language.

Another limitation is that it has a false impression of learning taking place. Learning process is not compatible with the straight lines (from the teacher's presentation of new knowledge, to controlled practice, and then to free production) emphasized in PPP, instead, it is a more complex and random, less linear process [1]. An additional criticism centers on the sequence of the structure that it is unnatural to follow the presentation-practice-production sequence firmly [7]. In response to this, Byrne [3] points out that the sequence can be more flexible instead of following the 'straight line' (Presentation, Practice and Production) rigidly. For instance, if students encounter some problems in the production stage, it would be feasible that the teacher presents the language items again, and then organizes the practice. The three elements are available, but the sequence of them is changeable due to the teaching materials, students' language proficiency and needs [4].
Last but not least, PPP may cause overuse of linguistic forms resulting from lack of practice and production of the target language in a real-life situation. It has been discussed in Section 2.2 that PPP focus on form instead of focus on meaning, which may lead to students' lack of communicative competence [11], and get bored by 'the mindless repetition of meaningless forms' [12].

\section{IMPLEMENTING PPP IN THE CHINESE EFL CONTEXT}

\subsection{Research Question and Method}

The research questions are: Which teaching approach do interviewees prefer in their classroom? TBLT or PPP. And what are the reasons for their preferences?

In order to tackle the questions, interview is selected as the research method. Ten English teachers from three distinctive secondary schools were invited as informants. Their teaching experience ranged from 2 to 25 years with 10 years being the average year. All of them own a teaching certificate and have a clear understanding of the theory and practice of PPP and TBLT.

\subsection{Findings}

The findings of the interview can be divided into two categories: one is the preference for PPP especially when teaching grammar, the other is the argument of the complexity of which method to take in practice.

Among ten secondary school English teachers, six teachers preferred PPP to TBLT and approximately all of them conveyed the complexity of classroom teaching and expressed it is difficult to use only one method in a lecture. As one of the informants who had 8 years of teaching experience put it:

Although the National English Teaching Standard requires us to teach based on Task-based Language Teaching, it is really difficult to perform a task in my classroom with 63 students. Once I designed a task talking about your favourite sport and the reasons why you like it in an Oral English class. I assigned them to talk about it in 10 groups, and each group selected one representative to make a presentation in front of the whole class. In the presentation stage the representatives were the several active students with relatively high language proficiency. However, in terms of grammar teaching, it is really feasible to take PPP. The presentation-practice-production procedure is suitable for no matter high or low proficiency students.

This informant stated that this task performed well among high proficiency students, nevertheless, some non-active students remained silent during the whole seminar. Besides, the large size of the classroom seems to be an obstacle to carry out a task since the teacher has difficulty in controlling the classroom.

Another interviewee with 25 years' teaching experience 
expressed the complexity of using a method in a Chinese EFL context. She stated the exam-oriented environment in Chinese secondary schools. In this context, a large number of students learn English simply to get a high score in the English exam to a higher educational institution. Thus, they care little about the daily communication but memorizing vocabulary and grammar in order to complete a reading comprehension exercise successfully. As she said, "The TBLT design and structure are good, but I'd like to use PPP which can get the less proficient students involved in my class".

\section{CONCLUSION}

Although PPP contains several limitations as discussed above, it might still be feasible in the Chinese EFL context especially in secondary schools. Firstly, unlike in UK or some western nations, most secondary school classrooms in China are large-size including 40 or more students, in which context it may encounter some discipline or classroom management problems when carrying out a task in groups. Secondly, the majority of students' motivation of learning English may lie in the passing the entrance examination for higher educational institution instead of learning for effective communication. Thirdly, most students have been used to learning new vocabulary and grammar by memorizing and drills and learn some new knowledge by teachers' explicit instruction since primary school. In the future research, more studies of the implementation of PPP in the Asian contexts could be conducted.

\section{REFERENCES}

[1] J. Harmer, The Practice of English Language Teaching. Harlow: Longman, 2007.

[2] D. Willis, Accuracy, fluency and conformity. In J. Willis \& D. Willis (Eds.), Challenge and change in language teaching (pp. 44-51). Oxford: Heinemann, 1996, pp. 44-51.

[3] D. Byrne, Teaching Oral English. Harlow:

Longman, 1986.

[4] D. Carless, Revisiting the TBLT versus PPP debate: Voices from Hong Kong. Asian Journal of English Language Teaching, 19 (2009) 49-66. DOI:

https://doi.org/10.1.1.707.9280

[5] C. Doughty, \& J. Williams, Issues and terminology. In C. Doughty \& J. Williams (Eds.), Focus on form in classroom second language acquisition, Cambridge, Cambridge University Press, 1998, pp. 1-11.

[6] J. Harmer, Is PPP dead? Modern English Teacher,

\section{$5(2)(1996) 1-17$.}

[7] S. Thornbury, How to teach grammar. Harlow, Longman, 1999.

[8] P. Skehan, A cognitive approach to language learning, Oxford University Press, 1998.

[9] P. Skehan, Second language acquisition research and task-based instruction. In J. Willis \& D. Willis (Eds.), Challenge and change in language teaching, Oxford, Heinemann, 1996, pp. 17-30.

[10] H-D. Brown, Principles of language learning and teaching, Pearson, 2007.

[11] D. Hymes, On communicative competence, University of Pennsylvania Press, 1971.

[12] A. Bruton, Task-based language teaching: For the state secondary FL classroom? Language Learning Journal, 31(1) (2005) 55-68. 